\title{
Effect of Chromium Content on Heat Treatment Behavior of Multi-Alloyed White Cast Iron for Abrasive Wear Resistance
}

\author{
Jatupon Opapaiboon ${ }^{1}$, Mawin Supradist Na Ayudhaya ${ }^{1, *}$, Prasonk Sricharoenchai ${ }^{1}$, \\ Sudsakorn Inthidech ${ }^{2}$ and Yasuhiro Matsubara ${ }^{3}$ \\ ${ }^{1}$ Department of Metallurgical Engineering, Faculty of Engineering, Chulalongkorn University, Bangkok, 10330, Thailand \\ ${ }^{2}$ Department of Manufacturing Engineering, Faculty of Engineering, Mahasarakham University, Mahasarakham, 44150, Thailand \\ ${ }^{3}$ National Institute of Technology, Kurume College, Kurume 830-8555, Japan
}

\begin{abstract}
The effect of chromium $(\mathrm{Cr})$ content on heat treatment behavior of multi-alloyed white cast iron with basic alloy composition of 5 mass $\%$ Mo, $\mathrm{W}$ and $\mathrm{V}$ each and 2 mass \% C was investigated. Cast iron with varying Cr content from 3 to $9 \%$ was prepared. Specimens were annealed at $1223 \mathrm{~K}$ and then hardened using fan air cooling from 1323 and $1373 \mathrm{~K}$ austenitizing. Hardened specimens were tempered between 673 and $873 \mathrm{~K}$ with $50 \mathrm{~K}$ intervals. In the as-cast state, the microstructure of specimens with $\mathrm{Cr}$ content less than 5 mass $\%$ consisted of primary austenite and eutectic structure of $(\gamma+\mathrm{MC})$ along with $\left(\gamma+\mathrm{M}_{2} \mathrm{C}\right)$. The $\left(\gamma+\mathrm{M}_{7} \mathrm{C}_{3}\right)$ was observed in specimens with $\mathrm{Cr}$ content of more than 5 mass $\%$. In as-hardened state, the hardness increased to the highest value at 5 mass $\% \mathrm{Cr}$ and subsequently decreased with an increase in the $\mathrm{Cr}$ content. The volume fraction of retained austenite $(\mathrm{V} \gamma)$ also behaved in the same way with reference to hardness. In the tempered state, evident secondary hardening was observed in all specimens. Maximum tempered hardness $\left(\mathrm{H}_{\mathrm{Tmax}}\right)$ was obtained at $773-798 \mathrm{~K}$ tempering. The $\mathrm{V} \gamma$ values decreased continuously as the tempering temperature increased and they were overall less than $5 \%$ at $\mathrm{H}_{\mathrm{Tmax}}$. The degree of secondary hardening $(\Delta \mathrm{Hs})$ increased proportionally with a rise of $\mathrm{V} \gamma$ in as-hardened state. The $\mathrm{H}_{\text {Tmax }}$ increased first and then decreased as the $\mathrm{Cr}$ content increased. The highest values of $\mathrm{H}_{\mathrm{Tmax}}$ were obtained in 5 mass $\% \mathrm{Cr}$ specimen regardless of austenitizing temperature.

[doi:10.2320/matertrans.M2018318]
\end{abstract}

(Received October 1, 2018; Accepted November 22, 2018; Published January 11, 2019)

Keywords: multi-alloyed white cast iron, Cr effect, heat treatment behavior, hardness, volume fraction of retained austenite

\section{Introduction}

Alloyed white cast irons have been utilized for a long time as parts or components of machines in steel-making, mining, cement and thermal plant industries due to extreme hardness and excellent abrasive wear resistance. ${ }^{1)}$ When minerals cause heavy abrasive damage to the surface of such parts or components during operation, the most important properties required for abrasive wear resistance are hardness and toughness. Therefore, there is a high demand for alloyed white cast iron with higher performance characteristics.

Alloyed white cast iron for rolling and pulverizing mill rolls has changed from low-alloyed white cast iron through $\mathrm{Ni}$-hard cast iron and high $\mathrm{Cr}$ cast iron, respectively. ${ }^{2)}$ High $\mathrm{Cr}$ cast iron has been used for a long time because of hardness and better abrasive wear resistance than Ni-hard cast iron. ${ }^{1,3-5)}$ Nevertheless, a disadvantage of this material is that a large volume fraction of eutectic chromium carbides reduces toughness of the cast iron.

In order to improve the final product, multi-alloyed white cast iron containing several kinds of strong carbide forming elements such as chromium (Cr), molybdenum (Mo), tungsten (W) and vanadium (V) was developed. ${ }^{5)}$ These elements combine with carbon (C) to form $\mathrm{MC}, \mathrm{M}_{2} \mathrm{C}$ and/or $\mathrm{M}_{7} \mathrm{C}_{3}$ eutectic carbides which have very high levels of hardness and improved abrasive wear resistance. ${ }^{6)}$ Cobalt (Co) is added to improve thermal properties, especially when the alloy is serviced at high temperature like hot rolling. The rest of alloying elements after forming their eutectic carbides dissolves into matrix and promotes the precipitation of secondary carbides during heat treatment.

*Corresponding author, E-mail: Mawin.S@chula.ac.th
The basic chemical composition of multi-alloyed white cast iron is 5 mass $\% \mathrm{Cr}$, Mo, W, V, Co each and 2 mass $\% \mathrm{C}$ (hereafter mass $\%$ is expressed by \%). ${ }^{5)} \mathrm{Cr}$ is not as strong a carbide former as the other elements; it is added because $\mathrm{Cr}$ forms discontinuous morphology of eutectic $\mathrm{M}_{7} \mathrm{C}_{3}$ carbide which improve toughness ${ }^{1,5,7-9)}$ and dissolves in austenite to significantly improve hardenability of the cast iron.

In reviewing the research on multi-alloyed white cast irons, systematic research on the role of $\mathrm{Cr}$ in the heat treatment processes is not found. ${ }^{10-12)}$ In this work, therefore, the effect of $\mathrm{Cr}$ content on heat treatment behavior (i.e., variation of hardness and volume fraction of retained austenite $\left(\mathrm{V}_{\gamma}\right)$ during heat treatment) was investigated using multi-alloyed white cast irons with $\mathrm{Cr}$ content from 3 to $9 \%$.

\section{Experimental Procedure}

\subsection{Preparation of test specimens}

The charge materials consisting of mild-steel, pig iron, ferro-alloys and pure metals were melted and superheated to $1853 \mathrm{~K}$. After being held at that temperature for 600 to $900 \mathrm{~s}$, the melt was poured from 1763 to $1793 \mathrm{~K}$ into preheated $\mathrm{CO}_{2}$ bonded sand molds in a round bar shape, as shown in Fig. 1. The substantial cavity size of the mold was $25 \mathrm{~mm}$ in diameter and $65 \mathrm{~mm}$ in length, together with sufficient riser. After pouring, the surface of the riser was covered instantly with dry exothermic powder to prevent the melt from cooling fast and oxidizing. The chemical compositions of the test specimens are presented in Table 1.

In each specimen, the parameter of carbon balance $\left(\mathrm{C}_{\mathrm{bal}}\right)$, which can estimate the $\mathrm{C}$ concentration in the matrix at equilibrium condition, ${ }^{6,13,14)}$ was calculated using the following equation (1), 
Table 1 Chemical composition and $\mathrm{C}_{\mathrm{bal}}$ value of test specimens.

\begin{tabular}{cccccccccc}
\hline \multirow{2}{*}{ Specimen } & \multicolumn{7}{c}{ Element (mass\%) } \\
& $\mathrm{C}$ & $\mathrm{Si}$ & $\mathrm{Mn}$ & $\mathrm{Cr}$ & $\mathrm{Mo}$ & $\mathrm{W}$ & $\mathrm{V}$ & $\mathrm{Co}$ & $\mathrm{C}_{\text {bal }}$ \\
\hline No.1 & 1.96 & 0.52 & 0.49 & 3.09 & 5.02 & 5.02 & 4.96 & 1.98 & 0.13 \\
\hline No.2 & 1.97 & 0.52 & 0.52 & 4.98 & 5.02 & 4.98 & 5.07 & 1.99 & 0 \\
\hline No.3 & 2.02 & 0.54 & 0.51 & 5.99 & 4.93 & 4.93 & 4.97 & 2.00 & -0.21 \\
\hline No.4 & 1.98 & 0.50 & 0.49 & 7.01 & 5.09 & 5.05 & 5.03 & 2.01 & -0.38 \\
\hline No.5 & 2.08 & 0.53 & 0.49 & 8.93 & 5.01 & 5.03 & 5.07 & 2.00 & -0.48 \\
\hline
\end{tabular}

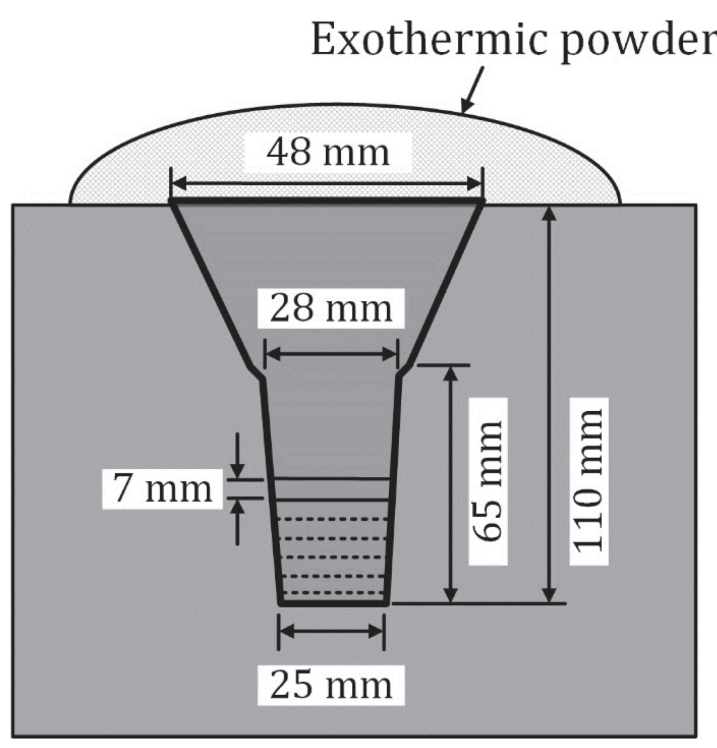

Fig. 1 Schematic drawing of $\mathrm{CO}_{2}$ bonded sand mold for test specimens.

$$
\mathrm{C}_{\mathrm{bal}}=\% \mathrm{C} \text { in cast iron }-\% \mathrm{C}_{\text {stoich }}
$$

Here, $\% \mathrm{C}$ is $\mathrm{C}$ content of specimen and $\% \mathrm{C}_{\text {stoich }}$ is the amount of $\mathrm{C}$ consumed to form carbides stoichiometrically. When the $\mathrm{M}_{7} \mathrm{C}_{3}$ carbide does not crystallize during solidification, the $\% \mathrm{C}_{\text {stoich }}$ can be calculated using eq. (2) which is availed for specimens with $\mathrm{Cr}$ content less than $5 \%$ (No. 1 and No. 2),

$$
\begin{aligned}
\% \mathrm{C}_{\text {stoich }}= & 0.060(\% \mathrm{Cr})+0.063(\% \mathrm{Mo})+0.033(\% \mathrm{~W}) \\
& +0.235(\% \mathrm{~V})
\end{aligned}
$$

In case that $\mathrm{M}_{7} \mathrm{C}_{3}$ carbide crystallizes, eq. (3) is used for calculation. This equation is availed for specimens with $\mathrm{Cr}$ content more than $5 \%$ (No. 3 to No. 5),

$$
\begin{aligned}
\% \mathrm{C}_{\text {stoich }}= & 0.099(\% \mathrm{Cr})+0.063(\% \mathrm{Mo})+0.033(\% \mathrm{~W}) \\
& +0.235(\% \mathrm{~V})
\end{aligned}
$$

\subsection{Heat treatment procedures}

The test ingots were coated with an anti-oxidation solution and annealed at $1223 \mathrm{~K}$ for $18 \mathrm{ks}$ in a furnace. The annealed ingots were sectioned using a wire-cutting machine to obtain disk-shape test pieces $7 \mathrm{~mm}$ in thickness. The specimens were austenitized at 1323 and $1373 \mathrm{~K}$ for $3.6 \mathrm{ks}$ and hardened using fan air cooling (FAC). The hardened specimens were tempered at $673-873 \mathrm{~K}$ with $50 \mathrm{~K}$ intervals for $12 \mathrm{ks}$ and cooled in still air.

\subsection{Microstructure observation}

The microstructure was observed using an Optical Microscope (OM) and Scanning Electron Microscope (SEM). The test pieces were polished using emery paper and buffered with $0.1 \mu \mathrm{m}$ alumina powder. To reveal the microstructure, Nital, Groesbeck's and Villela's reagents were used. In this paper, lots of secondary carbides are observed in matrix. The secondary carbides are formed from austenite and martensite. The carbides from as-cast austenite while austenitizing are relatively larger in size because precipitation and growth of carbides are fast at high temperature. On the other side, the carbides from retained austenite after quenching and from martensite during tempering are fine because the reactions take place at low temperature. Then, the secondary carbides in large and small sizes co-exist in the matrix. However, it is hard to define the two kinds of carbides, because the carbides cannot be separated clearly. Therefore, authors call them as secondary carbide all together.

\subsection{Measurement of hardness and volume fraction of retained austenite $(\mathrm{V} \gamma)$}

The macro-hardness was measured using Vickers hardness tester with a load of $294.2 \mathrm{~N}$ (30 kgf) and micro-hardness using Micro-Vickers hardness tester with a load of $0.98 \mathrm{~N}$ (100 gf). The measurement was performed in five random locations and the values were averaged.

The volume fraction of retained austenite $\left(\mathrm{V}_{\gamma}\right)$ was measured using a X-ray diffraction method developed for alloyed white cast iron. ${ }^{11,14,15)}$ The goniometer with special sample stage enabled the test piece to rotate and swing simultaneously and cancel the effect of preferred crystal orientation of austenite. Mo- $\mathrm{K}_{\alpha}$ characteristic line with a wavelength of $0.0711 \mathrm{~nm}$ was used as a source of X-ray 
beam. The scanning range was from 24 to 44 degree by $2 \theta$. For quantitative calculation, $(200)_{\alpha}$ and $(220)_{\alpha}$ planes for ferrite $(\alpha)$ or martensite as $(220)_{\gamma}$ and $(311)_{\gamma}$ planes for austenite $(\gamma)$ were adopted, respectively. The integrated area of the inner side of every peak was measured using an image analyzer. The calculation of $\mathrm{V} \gamma$ was done for three combinations of peaks, $(220)_{\alpha}-(311)_{\gamma},(200)_{\alpha}-\Sigma(220,311)_{\gamma}$ and $\Sigma(200,220)_{\alpha^{-}}(311)_{\gamma}$ and the average value was adopted.

\section{Results and Discussions}

\subsection{As-cast microstructure of specimens}

The typical as-cast microstructures of test specimens were observed using $\mathrm{OM}$ and are shown in Fig. 2. All the specimens showed hypoeutectic composition consisting of primary austenite dendrite $\left(\gamma_{\mathrm{P}}\right)$ and eutectic structure $(\gamma+$ eutectic carbide). The type and morphology of phase exist in multi-alloyed white cast iron was clarified by $\mathrm{Wu}$ et al. ${ }^{6)}$ and Hashimoto et al. ${ }^{16)}$ They reported that the eutectic carbides in multi-alloyed white cast iron with basic alloy composition are mostly $\mathrm{MC}$ and $\mathrm{M}_{2} \mathrm{C}$ types but very small amount of $\mathrm{M}_{7} \mathrm{C}_{3}$ type co-exists. The morphology of $\mathrm{MC}$ carbide is modular while the $\mathrm{M}_{2} \mathrm{C}$ carbide is fine lamellar. The eutectic $\mathrm{M}_{7} \mathrm{C}_{3}$ carbide is rod-like or ledeburitic. The type of carbide can be distinguished by etching with Groesbeck's reagents, that is, the $\mathrm{M}_{2} \mathrm{C}$ and $\mathrm{M}_{7} \mathrm{C}_{3}$ carbides are colored but $\mathrm{MC}$ carbide is not. $\left.{ }^{6}\right)$ From the color etching, it

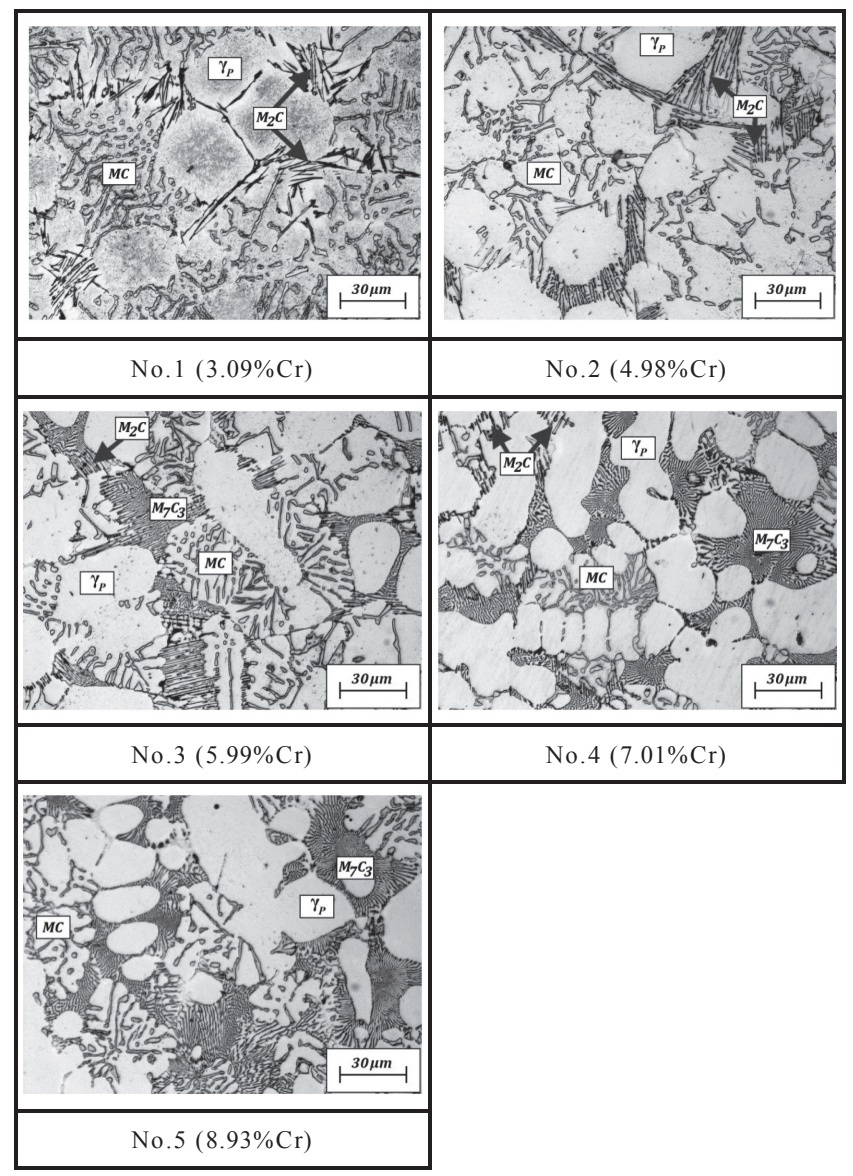

Fig. 2 Microstructures of as-cast specimens with different $\mathrm{Cr}$ contents (by $\mathrm{OM})$

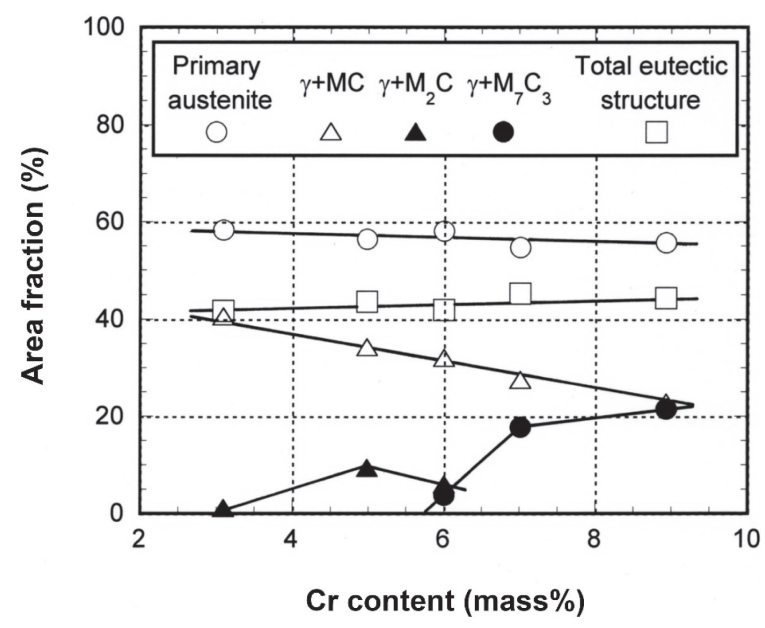

Fig. 3 Relationship between area fractions of primary austenite $\left(\gamma_{\mathrm{P}}\right)$, kind of eutectic structure and $\mathrm{Cr}$ content in the as-cast specimens.

is found that eutectics of $(\gamma+\mathrm{MC})$ and $\left(\gamma+\mathrm{M}_{2} \mathrm{C}\right)$ exist in the specimens with 3 and $5 \% \mathrm{Cr}$. In the specimen with $6 \% \mathrm{Cr}$, the eutectic of $\left(\gamma+\mathrm{M}_{7} \mathrm{C}_{3}\right)$ began to crystallize, taking the place of $\left(\gamma+\mathrm{M}_{2} \mathrm{C}\right)$ eutectic. In the specimen with $7 \% \mathrm{Cr}$, the $\left(\gamma+\mathrm{M}_{2} \mathrm{C}\right)$ eutectic was much less. In the specimen with $9 \% \mathrm{Cr}$, the eutectic structures were mostly $(\gamma+\mathrm{MC})$ and $\left(\gamma+\mathrm{M}_{7} \mathrm{C}_{3}\right)$.

In order to identify how $\mathrm{Cr}$ content affects the fraction of phases crystallizing from liquid, the area fraction of primary austenite dendrite $\left(\gamma_{\mathrm{P}}\right)$ and each type of the eutectic in the as-cast specimens were measured and the relationship is shown in Fig. 3. The amount of $\gamma_{\mathrm{P}}$ decreased very slightly and $(\gamma+\mathrm{MC})$ eutectic did so gradually. On the contrary, $\left(\gamma+\mathrm{M}_{2} \mathrm{C}\right)$ and $\left(\gamma+\mathrm{M}_{7} \mathrm{C}_{3}\right)$ eutectics increased as $\mathrm{Cr}$ content rose, except for specimen No. 3 with $6 \% \mathrm{Cr}$ in which $(\gamma+\mathrm{MC}),\left(\gamma+\mathrm{M}_{2} \mathrm{C}\right)$ and $\left(\gamma+\mathrm{M}_{7} \mathrm{C}_{3}\right)$ eutectics co-exist. At $6 \% \mathrm{Cr}$, the $\mathrm{Cr}$ began to display inhibition of $\left(\gamma+\mathrm{M}_{2} \mathrm{C}\right)$ crystallization and instead promoted the nucleation of $\left(\gamma+\mathrm{M}_{7} \mathrm{C}_{3}\right)$ eutectic, respectively. It was observed that the $\left(\gamma+\mathrm{M}_{7} \mathrm{C}_{3}\right)$ eutectic started to crystallize in $6 \% \mathrm{Cr}$ cast iron.

\subsection{Behavior of hardness and $\mathbf{V}$ in as-hardened state}

It was reported that the eutectic carbide changed little during austenitizing except for $\mathrm{M}_{2} \mathrm{C}$ carbide which might decompose when being held at high temperature for long time. ${ }^{17)}$ On the other hand, the matrix changed widely depending on the heat treatment condition. During austenitizing, the retained austenite in the as-cast state is destabilized by the precipitation of secondary carbides. This reduces the stability of austenite and allows the transformation of austenite into martensite during post cooling.

SEM microphotographs of all as-hardened specimens are shown in Fig. 4. The matrix of each specimen is composed of martensite $(\mathrm{M})$, retained austenite $\left(\gamma_{\mathrm{R}}\right)$ and fine secondary carbides (SC). It is evident that the secondary carbide precipitated during austenitizing. However, the variation of the amount could not be made clear in the microphotographs. Also, the types of secondary carbides could not be identified using SEM but only TEM analysis because the sizes are too fine to analyze alloy concentration quantitatively. However, Hashimoto et al. ${ }^{18)}$ reported using XRD and TEM that the secondary carbides in as-hardened state were $\mathrm{MC}, \mathrm{M}_{6} \mathrm{C}$ and 


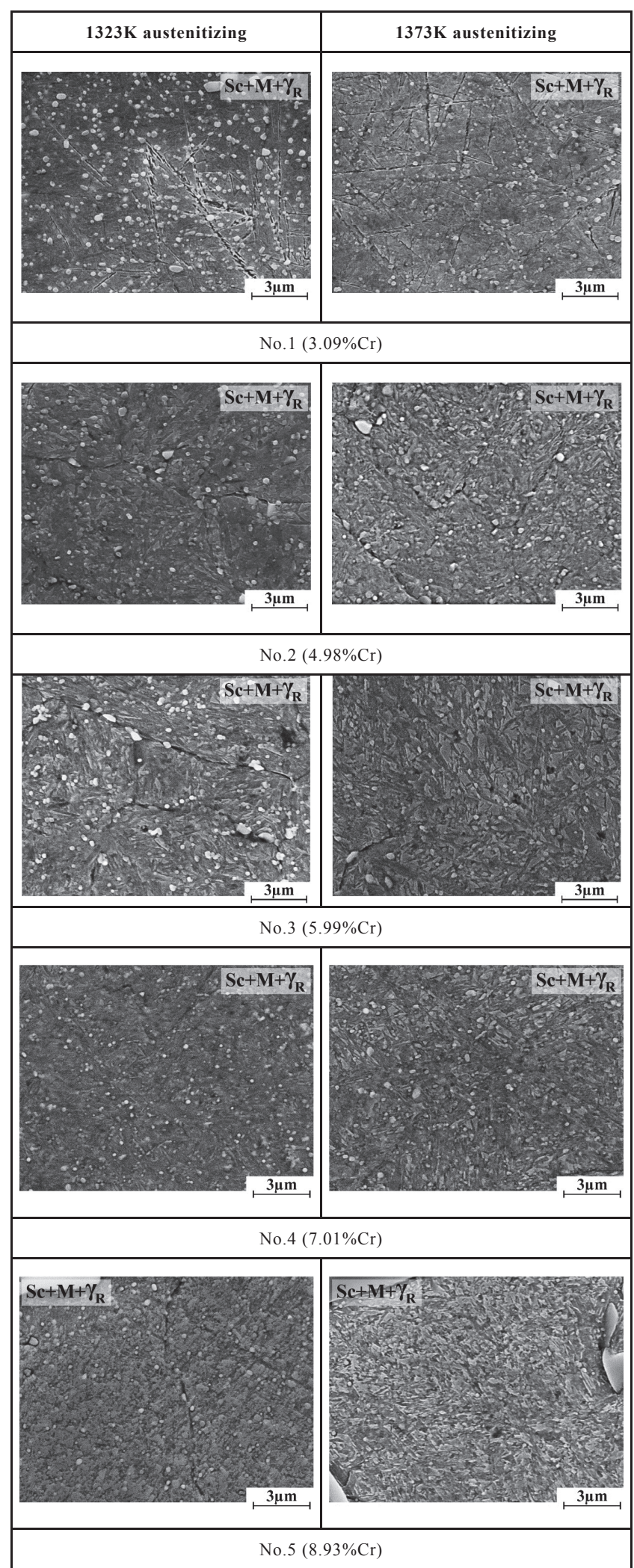

Fig. 4 Typical matrix microstructures of as-hardened specimens with different $\mathrm{Cr}$ contents (by SEM)

$\mathrm{M}_{7} \mathrm{C}_{3}$ types. In as-hardened matrix, martensite phases transformed from destabilized austenite are clearly observed in all of specimens (Fig. 4). In addition, the amount of retained austenite seems to be greater in the specimens hardened from higher temperature.

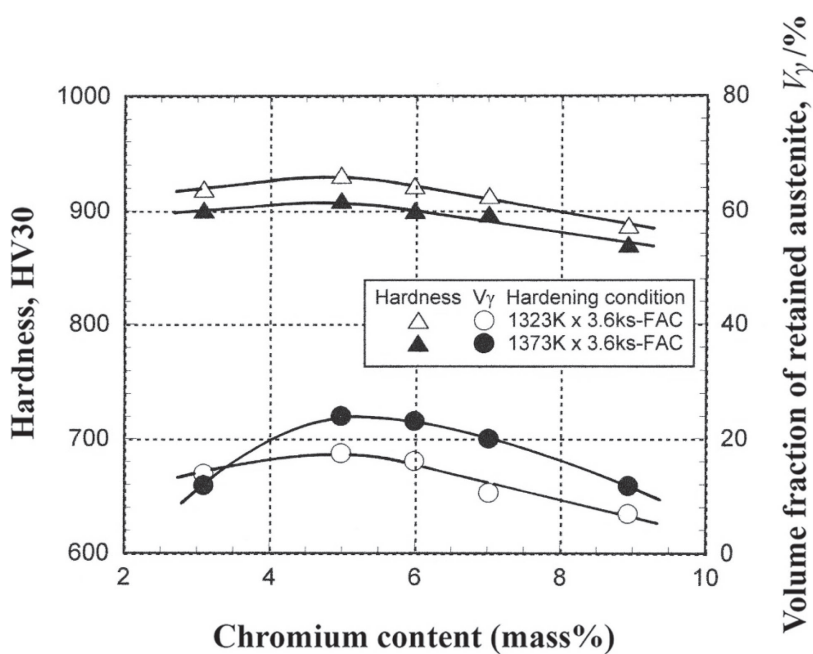

Fig. 5 Relationship between macro-hardness, volume fraction of retained austenite $\left(\mathrm{V}_{\gamma}\right)$ and $\mathrm{Cr}$ content in as-hardened state.

The effect of $\mathrm{Cr}$ content on macro-hardness and $\mathrm{V} \gamma$ in as-hardened state is shown in Fig. 5. The macro-hardness increased a little to the maximum value at $5 \% \mathrm{Cr}$ and afterward decreased gradually as $\mathrm{Cr}$ content rose. The slight increase in hardness in the former stage from 3 to $5 \% \mathrm{Cr}$ could be because $\mathrm{Cr}$ dissolved in the matrix not only improved the hardenability, but also strengthened the matrix. In addition, an increase in $\mathrm{Cr}$ content promoted the precipitation of secondary carbides. A decrease in the hardness in the latter stage over $5 \% \mathrm{Cr}$ shows in Fig. 3 that the amount of $\left(\gamma+\mathrm{M}_{7} \mathrm{C}_{3}\right)$ eutectic with low hardness increased and those of $(\gamma+\mathrm{MC})$ and $\left(\gamma+\mathrm{M}_{2} \mathrm{C}\right)$ eutectics with high hardness decreased as $\mathrm{Cr}$ content rose. Besides, as the $\mathrm{C}_{\mathrm{bal}}$ of specimen falls, the hardness of martensite decreases due to reduction of $\mathrm{C}$ in martensite. On the other hand, the $\mathrm{V} \gamma$ increased gradually to the highest value at $5 \% \mathrm{Cr}$ and then decreased slowly. At the former stage, the $\mathrm{Cr}$ dissolved in austenite lowered Ms temperature and consequently, the $\mathrm{V} \gamma$ increased. At the latter stage, the $\mathrm{V} \gamma$ continued to decrease. This is because Ms temperature in multi-alloyed white cast iron increases as the $\mathrm{Cr}$ content rises over $5 \%{ }^{19)}$ The $\mathrm{V} \gamma$ value is overall high in the case of high austenitizing temperature like $1373 \mathrm{~K}$, and there, the solubility of $\mathrm{C}$ and alloying elements in austenite was increased. These elements, dissolved more in austenite, made Ms temperatures lower. At $3 \% \mathrm{Cr}$, the $\mathrm{V} \gamma$ values of specimens hardened from each austenitizing temperature were nearly the same.

The hardness of specimens hardened from $1323 \mathrm{~K}$ are greater than those hardened from $1373 \mathrm{~K}$, regardless of $\mathrm{Cr}$ content. The reason is that the low austenitizing temperature produces less $\mathrm{V} \gamma$ than high austenitizing temperature does.

As mentioned previously, the eutectic carbides change little during heat treatment; that is, the variation of macrohardness is mainly caused by matrix microstructure. The effect of $\mathrm{V} \gamma$ on micro-hardness in the as-hardened state is shown in Fig. 6. The micro-hardness rose gradually in proportion to the $\mathrm{V} \gamma$ in the case of $1323 \mathrm{~K}$ austenitizing, and slightly in $1373 \mathrm{~K}$ austenitizing. The maximum microhardness was obtained at $17 \%$ in the specimen hardened from 


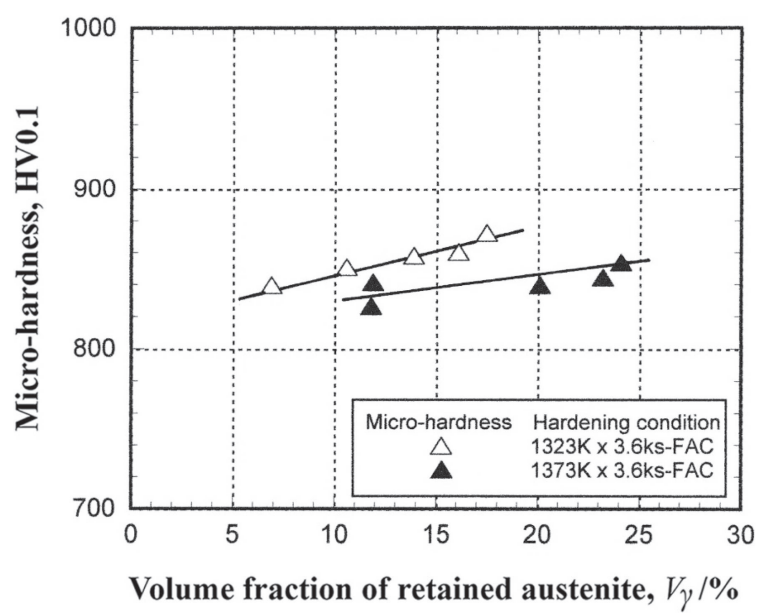

Fig. 6 Relationship between micro-hardness and volume fraction of retained austenite $\left(\mathrm{V}_{\gamma}\right)$ in as-hardened state.

$1323 \mathrm{~K}$, and $24 \% \mathrm{~V} \gamma$ in hardening from $1373 \mathrm{~K}$. The reason for the increase is that an increase in $\mathrm{V} \gamma$ is equivalent to the increase of $\mathrm{C}_{\mathrm{bal}}$ of specimen. When $\mathrm{C}_{\mathrm{bal}}$ rises, therefore, the precipitation of secondary carbides increases.

\subsection{Behavior of hardness and $V \boldsymbol{\gamma}$ in a tempered state}

In general, the $\mathrm{V}_{\gamma}$ decreases as tempering temperature is elevated because the retained austenite is destabilized by precipitation of secondary carbides. It is difficult to identify the type and morphology of secondary carbides in tempered state using SEM analysis. However, it is reported that the secondary carbides in heat-treated multi-alloyed white cast iron with basic composition were mostly $\mathrm{MC}, \mathrm{M}_{6} \mathrm{C}$ and $\mathrm{M}_{7} \mathrm{C}_{3}$ types based on TEM analysis. ${ }^{16)}$ Due to the precipitation of secondary carbides, C concentration, as well as alloying elements in austenite, decreases, and this makes $\mathrm{Ms}$ temperature rise. This result enables the residual austenite to transform into bainite or martensite during cooling.

The relationship between macro-hardness, $\mathrm{V}_{\gamma}$ and the tempering temperature of all specimens is shown in Fig. 7. The secondary hardening is observed in all the hardness curves and occurs due to the precipitation of secondary carbides and martensite transformation from the residual austenite during cooling after tempering. The hardness specifically drops from as-hardened state at the lowest tempering temperature of $673 \mathrm{~K}$. Then, it increases to the maximum point or the maximum tempered hardness $\left(\mathrm{H}_{\mathrm{Tmax}}\right)$ as the temperature is evaluated and after that, it decreases remarkably. In most of specimens, the $\mathrm{H}_{\text {Tmax }}$ are obtained at 773 and $798 \mathrm{~K}$ tempering. The higher austenitizing temperature provides greater $\mathrm{H}_{\text {Tmax }}$ value. On the other side, the $\mathrm{V} \gamma$ decreases gradually as the temperature increases to $723 \mathrm{~K}$ and it continues to drop steeply when the temperature rises over $723 \mathrm{~K}$. The $\mathrm{V} \gamma$ value at $\mathrm{H}_{\text {Tmax }}$ is less than $5 \%$ regardless of both the $\mathrm{Cr}$ content and austenitizing temperature. At each austenitizing temperature, the tempering temperature obtained $\mathrm{H}_{\text {Tmax }}$ shifts to the low temperature side as $\mathrm{Cr}$ content increases over $6 \%$. The reason is that the $\mathrm{C}$ concentration in austenite reduces with an increase in $\mathrm{Cr}$ content. In such specimens, therefore, the lower tempering temperature is enough to complete the precipitation of secondary carbides which are necessary to get $\mathrm{H}_{\text {Tmax }}$. The decrease in hardness over the temperature at the $\mathrm{H}_{\mathrm{Tmax}}$ could be due to coarsening of fine carbides, tempering of martensite, as well as the simultaneous reduction of $\mathrm{V}_{\gamma}$. Powell and Laird ${ }^{20)}$ suggested that the precipitation of secondary carbides in high $\mathrm{Cr}$ cast iron occurs in the short time during tempering and, after that, the carbides begin to aggromerate. This behavior could lead to the coarsening of secondary carbides.

Based on the above results, it is clear that the hardness of specimen or macro-hardness varies depending on the type and amount of eutectic carbide and the matrix structure. It is also known that the hardness of eutectic carbide changes little at room temperature, even if heat treatment was involved. In the same cast iron, therefore, the variation of macro-hardness depends on the matrix hardness. The relationship between $\mathrm{V} \gamma$ and macro-hardness and micro-hardness in tempered state are shown in Fig. 8(a) and (b), respectively. Of course, the distribution of macro-hardness lies at higher hardness than that of micro-hardness, however, there is a little variation in both types of hardness. The hardness increases markedly to the maximum value at about $4 \% \mathrm{~V} \gamma$ and then decreases gradually as the $\mathrm{V} \gamma$ increases. The reason for the decrease is that an excess of soft retained austenite remains in the matrix together with a decrease in martensite. At the same $\mathrm{V} \gamma$ value, the specimens hardened from $1373 \mathrm{~K}$ have greater hardness on the whole than those hardened from $1323 \mathrm{~K}$. The fact is that greater secondary hardening is obtained in the specimens hardened from high temperature. The greatest hardness is obtained in the specimen No. 2 with 5\%Cr. Regardless of the austenitizing temperature, the macro-hardness of more than 900 HV30 and micro-hardness over 800 HV0.1 are obtained between 1 to $10 \% \mathrm{~V} \gamma$ and 1 to $18 \% \mathrm{~V} \gamma$, respectively. As shown in Fig. 8(b), in the region of less than $2 \% \mathrm{~V} \gamma$, the micro-hardness is scattered broadly from a very low value of 540 to $860 \mathrm{HV0.1}$. In order to make this reason clear, the relation of micro-hardness vs. tempering temperature is arranged and shown in Fig. 9. It is found that the hardness decreases as the tempering temperature increases. This evidence illustrates that a decrease in hardness is due to the coarsening of secondary carbides and transformation of austenite to ferrite or pearlite with an increase in tempering temperature. At the highest tempering temperature of $873 \mathrm{~K}$, however, the micro-hardness is very low and still lie widely. This broad dispersion of hardness comes from the $\mathrm{Cr}$ content in specimen. As $\mathrm{Cr}$ content increases, more $\mathrm{Cr}$ carbide which has lower hardness, precipitates in the matrix and causes the micro-hardness to be very low. Moreover, the hardness tempered at $873 \mathrm{~K}$ decreases in the order of $\mathrm{Cr}$ content of specimens even if the hardening temperature is different.

The effect of $\mathrm{Cr}$ content on maximum tempered macrohardness $\left(\mathrm{H}_{T \max }\right)$ and $\mathrm{V} \gamma$ at $\mathrm{H}_{\text {Tmax }}\left(\mathrm{V}_{\gamma \text {-HTmax }}\right)$ is shown in Fig. 10. As the $\mathrm{Cr}$ content rises, the $\mathrm{H}_{\mathrm{Tmax}}$ increases to the highest value at $5 \% \mathrm{Cr}$ and decreases progressively with a rise of the $\mathrm{Cr}$ content over $5 \%$. The $\mathrm{H}_{\mathrm{Tmax}}$ values of 913 and 932 HV30 were obtained in the cases of austenitizing temperatures at 1323 and $1373 \mathrm{~K}$, respectively. The former is caused by an increase in the amount of precipitated secondary carbides and martensite transformed from destabilized austenite. In addition to this, an increase in total amount of eutectics of $(\gamma+\mathrm{MC})$ and $\left(\gamma+\mathrm{M}_{2} \mathrm{C}\right)$ can boost the hardness. 


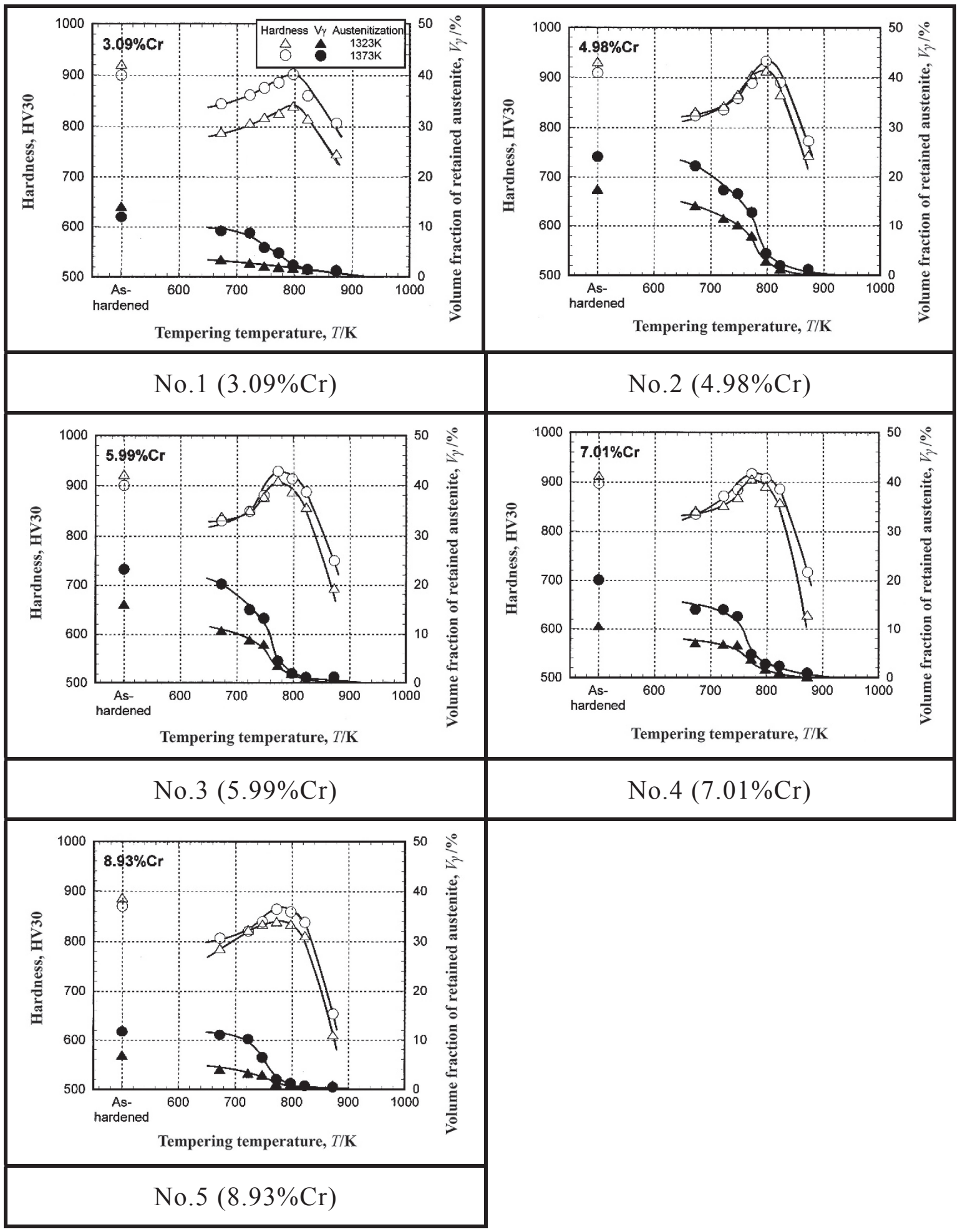

Fig. 7 Relationship between macro-hardness, volume fraction of retained austenite $\left(\mathrm{V}_{\gamma}\right)$ and tempering temperatures of specimens with different Cr contents.

The latter behavior is due to an increase in eutectic $\mathrm{M}_{7} \mathrm{C}_{3}$ carbide, which has lower hardness than $\mathrm{MC}$ and $\mathrm{M}_{2} \mathrm{C}$ carbides together with a decrease in the hardness of martensite with low $\mathrm{C}$ concentration. As for the $\mathrm{V} \gamma$ at $\mathrm{H}_{\text {Tmax }}$ $\left(\mathrm{V}_{\gamma \text {-HTmax }}\right)$, it is clear the difference in $\mathrm{V} \gamma$ values among the specimens are small and overall are less than 5\% regardless of $\mathrm{Cr}$ content. This proves that a certain amount of austenite remains in the specimens with $\mathrm{H}_{\text {Tmax }}$ even after tempering.
Looking back at Fig. 8, it is clear that the $\mathrm{V} \gamma$ in as-hardned state is closely connected to the tempered hardness of specimens. So, the relation between $\mathrm{H}_{\text {Tmax }}$ vs. $\mathrm{V} \gamma$ values was clarified and is shown in Fig. 11. The $\mathrm{H}_{\text {Tmax }}$ increased roughly in proportion to the $\mathrm{V} \gamma$ in the range of $5-25 \%$; the greater amount of $\mathrm{V} \gamma$ in the as-hardned state, the higher $\mathrm{H}_{\text {Tmax }}$. It is known that the $\mathrm{V} \gamma$ in as-hardened state depends on the amount of $\mathrm{C}$ and alloying elements dissolving in 

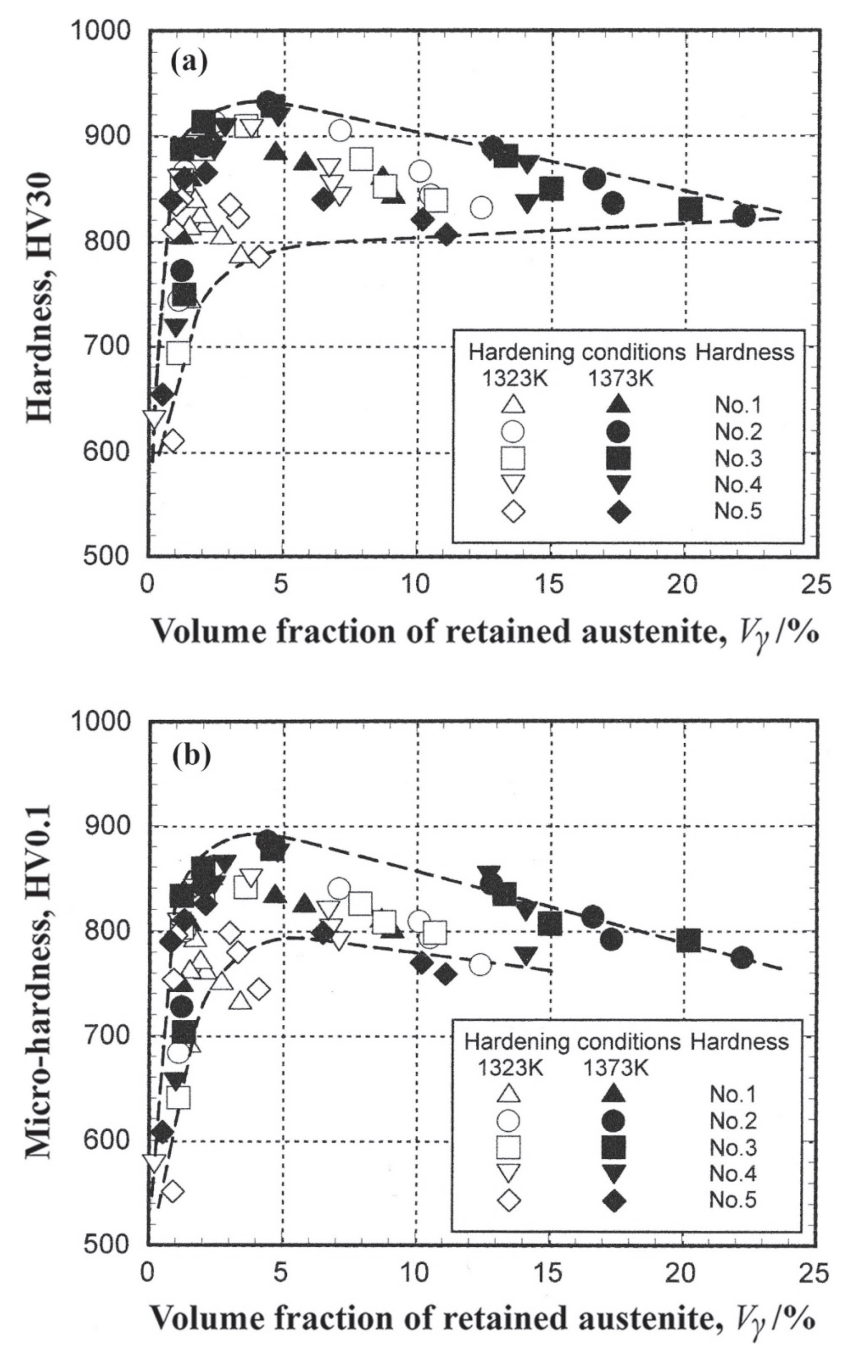

Fig. 8 Relationship between hardness and volume fraction of retained austenite $\left(\mathrm{V}_{\gamma}\right)$ in tempered state. (a) Macro-hardness, (b) Micro-hardness.

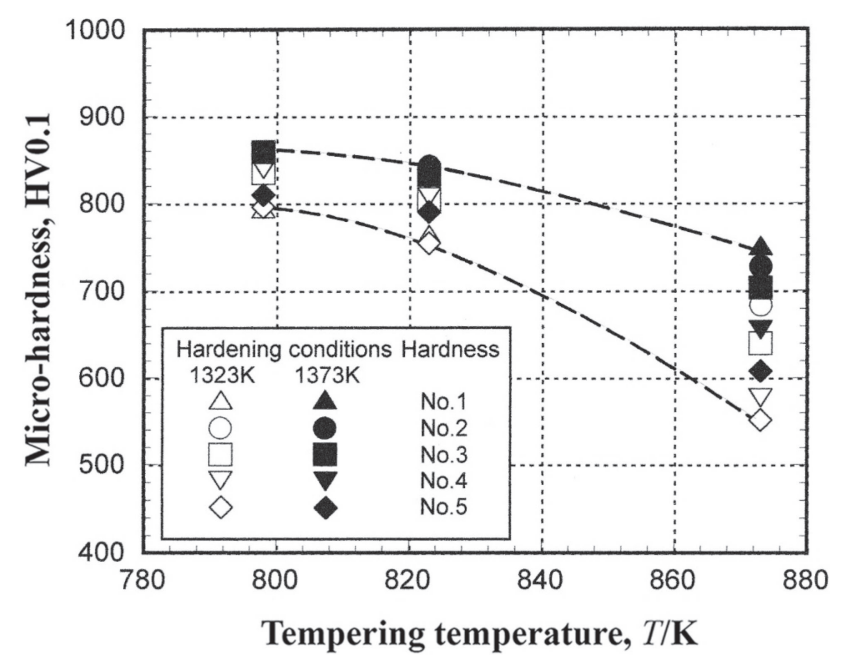

Fig. 9 Relationship between micro-hardness and tempering temperature of specimens with volume fraction of retained austenite $\left(\mathrm{V}_{\gamma}\right)$ less than $2 \%$.

matrix. In as-hardened state, more $\mathrm{C}$ and other alloying elements are supersaturated in the austenite and it promotes more precipitation of secondary carbides. At the same time, the martensite is also supersaturated with $\mathrm{C}$ and alloying elements and it precipitates secondary carbide with high

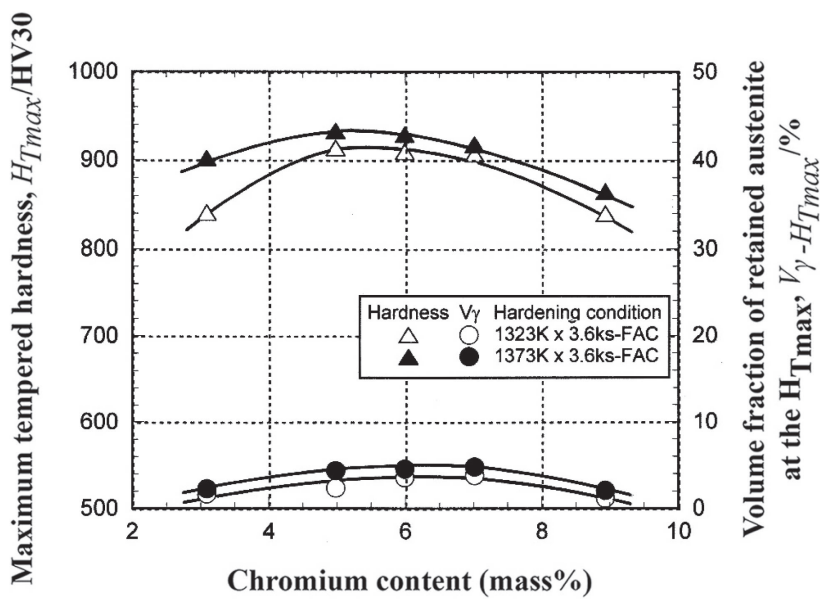

Fig. 10 Relationship between maximum tempered hardness $\left(\mathrm{H}_{\mathrm{Tmax}}\right)$, volume fraction of retained austenite $\left(\mathrm{V}_{\gamma}\right)$ at $\mathrm{H}_{\mathrm{Tmax}}$ and $\mathrm{Cr}$ content.

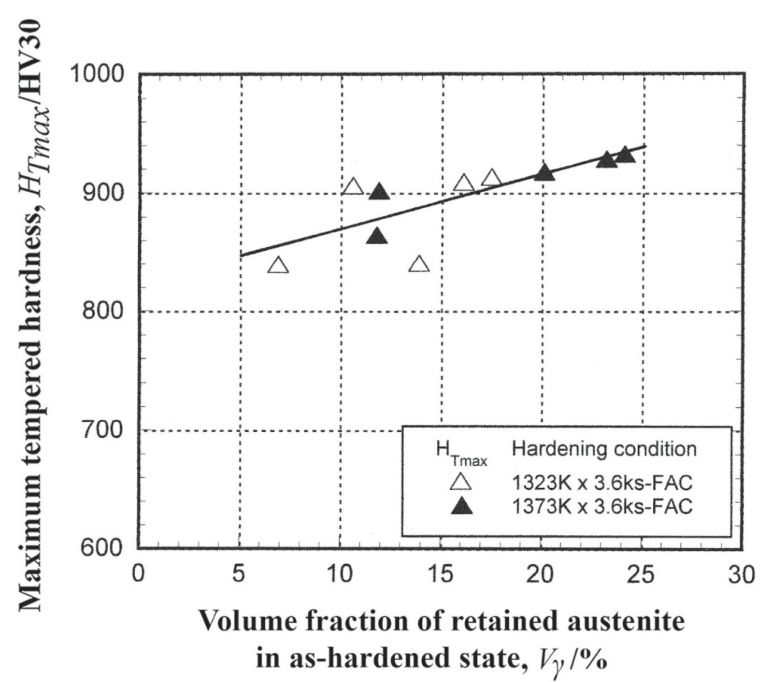

Fig. 11 Relationship between maximum tempered hardness $\left(\mathrm{H}_{\mathrm{Tmax}}\right)$ and volume fraction of retained austenite $\left(\mathrm{V}_{\gamma}\right)$ in as-hardened state.

hardness during tempering. Therefore, it can be said that the more $\mathrm{V} \gamma$, the more precipitation of secondary carbides. Here, it can be seen that $\mathrm{V} \gamma$ of more than $17 \%$ in as-hardned state is needed to get the $\mathrm{H}_{\text {Tmax }}$ over 900 HV30 by tempering.

As illustrated in Fig. 7, the hardnes curves showed greater or lesser secondary hardening, depending on the $\mathrm{Cr}$ content and austentizing temperature. In order to clarify how $\mathrm{Cr}$ content affects secondary hardening, the degree of secondary hardening $(\Delta \mathrm{Hs})$, which is expressed by the difference in the hardness between $\mathrm{H}_{T \max }$ and the hardness where the secondary hardening begins, is calculated. The relationship between $\Delta \mathrm{Hs}$ and $\mathrm{Cr}$ content is shown in Fig. 12. In the region of $\mathrm{Cr}$ content more than $5 \%$, the $\Delta \mathrm{Hs}$ decreased in proportion to the $\mathrm{Cr}$ content in each case of austenitizing temperature. However, the $\Delta \mathrm{Hs}$ values are more in $1373 \mathrm{~K}$ austenitizing than those in $1323 \mathrm{~K}$. In spite of a decrease in $\mathrm{Cr}$ content, the $\Delta \mathrm{Hs}$ of $3 \% \mathrm{Cr}$ specimen was low. This is because Ms temperature is higher than that of the $5 \% \mathrm{Cr}$ specimen. ${ }^{19)}$ So, it is reasonable that the $\mathrm{V} \gamma$ value and $\Delta \mathrm{Hs}$ in $3 \% \mathrm{Cr}$ specimen decreased more than those of $5 \% \mathrm{Cr}$ specimen. From such a remarkable change in the $\Delta \mathrm{Hs}$, it was determined that the $\Delta \mathrm{Hs}$ could also be closely related to 


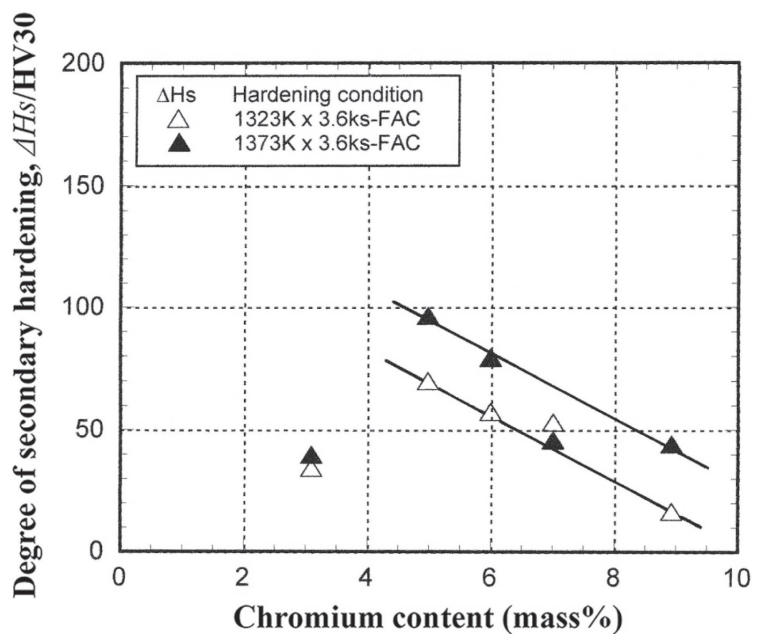

Fig. 12 Effect of $\mathrm{Cr}$ content on degree of secondary hardening $(\Delta \mathrm{Hs})$.

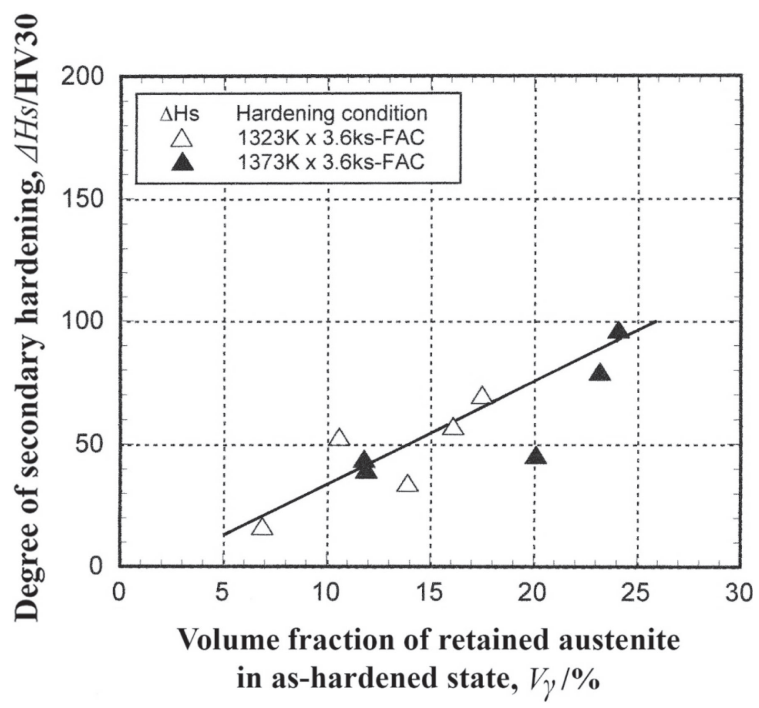

Fig. 13 Relationship between degree of secondary hardening $(\Delta \mathrm{Hs})$ and volume fraction of retained austenite $\left(\mathrm{V}_{\gamma}\right)$ in as-hardened state.

the $\mathrm{V} \gamma$ in as-hardened state. The relationship is shown in Fig. 13. The $\Delta \mathrm{Hs}$ increased proportionally to an increase of $\mathrm{V} \gamma$ in as-hardened state, regardless of austenitizing temperature. This figure supports the result in Fig. 11 that the greater the amount of $\mathrm{V} \gamma$ in as-hardened state provided the higher the $\mathrm{H}_{\text {Tmax }}$. It is because more $\mathrm{V} \gamma$ causes more reactions to increase the hardness by the secondary hardening mechanism. However, it should be noted that too much $\mathrm{V} \gamma$ in the as-hardened state may lead a reduction of hardness in the tempered state because a great amount of austenite may be left in the matrix, even after tempering.

As described before, the $\Delta \mathrm{Hs}$ is closely related to the $\mathrm{H}_{\text {Tmax }}$. Therefore, the relationship between $\mathrm{H}_{T \max }$ and the $\Delta \mathrm{Hs}$ is summarized and shown in Fig. 14. The $\mathrm{H}_{\text {Tmax }}$ rose to $900 \mathrm{HV} 30$ at $\Delta \mathrm{Hs}$ of $50 \mathrm{HV} 30$, and then the $\mathrm{H}_{\mathrm{Tmax}}$ increased slightly as the $\Delta \mathrm{Hs}$ rose. The result shows that a larger amount of $\Delta \mathrm{Hs}$ provides higher $\mathrm{H}_{\mathrm{Tmax}}$, similar to the relationship between $\mathrm{H}_{T \max }$ vs. $\mathrm{V} \gamma$ in as-hardened state.

Here, it should be of interest to note how closely the net value of austenite is directly connected to $\Delta \mathrm{Hs}$. The difference between the $\mathrm{V} \gamma$ in as-hardened state and that

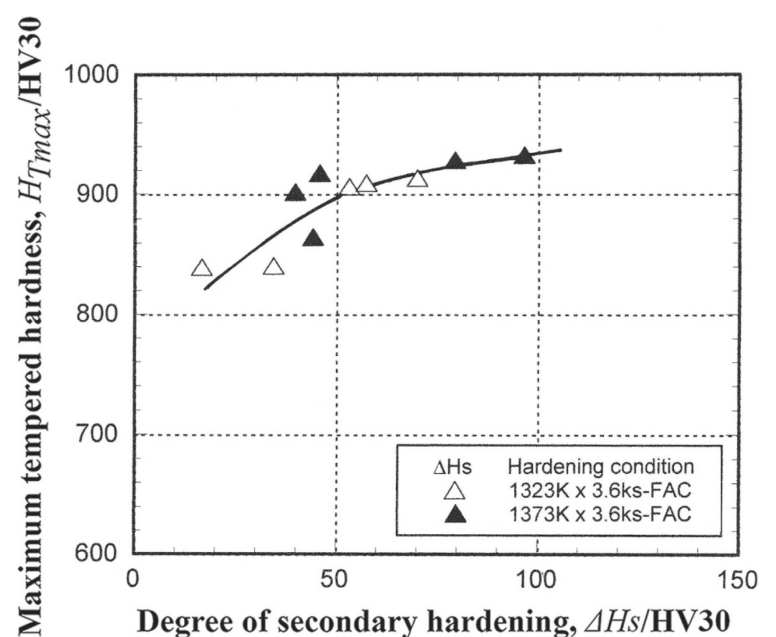

Fig. 14 Relationship between maximum tempered hardness $\left(\mathrm{H}_{\mathrm{Tmax}}\right)$ and degree of secondary hardening $(\Delta \mathrm{Hs})$.

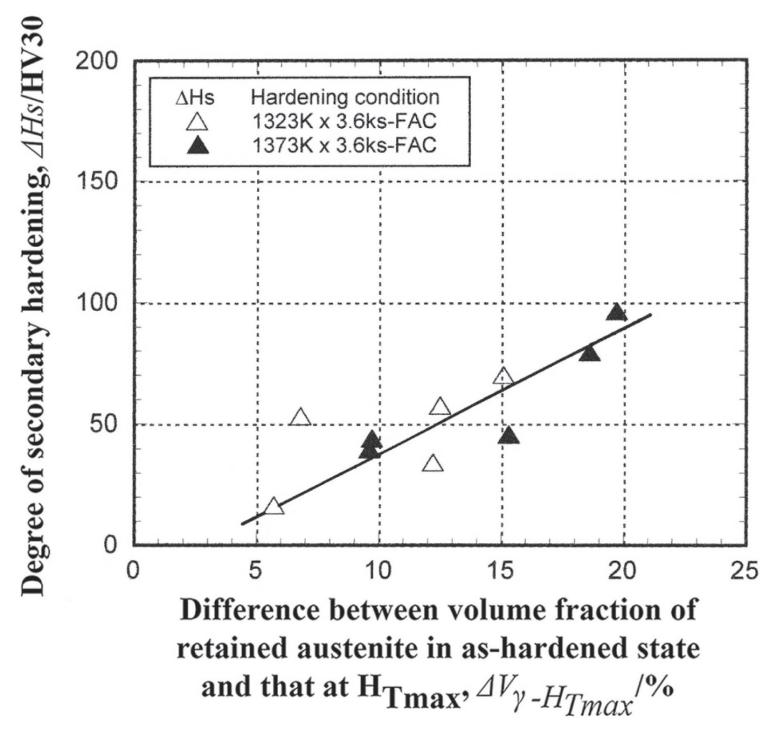

Fig. 15 Relationship between degree of secondary hardening $(\Delta \mathrm{Hs})$ and difference between volume fraction of retained austenite in as-hardened state and that at $\mathrm{H}_{\mathrm{Tmax}}\left(\Delta \mathrm{V}_{\gamma \text {-HTmax }}\right)$.

at $\mathrm{H}_{\mathrm{Tmax}}\left(\Delta \mathrm{V}_{\gamma \text {-HTmax }}\right)$ is calculated for each specimen and the relationship is shown in Fig. 15. The $\Delta \mathrm{Hs}$ increased proportionally to increase in $\Delta \mathrm{V}_{\gamma \text {-HTmax }}$. It is clear that the net amount of austenite $\left(\Delta \mathrm{V}_{\gamma-\mathrm{HTmax}}\right)$ is directly related to the $\mathrm{H}_{\text {Tmax }}$. Figure 14 also shows that the $\Delta \mathrm{Hs}$ value above $50 \mathrm{HV} 30$ is necessary to achieve $\mathrm{H}_{\text {Tmax }}$ over 900HV30. Figure 15 , on the other hand, demonstrates that $\Delta \mathrm{V}_{\gamma \text {-HTmax }}$ greater than $12 \%$ is required and this value is near to $14 \% \mathrm{~V} \gamma$ in the as-hardened state shown in Fig. 13.

\section{Conclusions}

The effect of chromium $(\mathrm{Cr})$ content on the heat treatment behavior of multi-alloyed white cast iron was investigated, varying $\mathrm{Cr}$ content from 3 to $9 \%$ under the basic chemical composition. Test pieces were hardened in a range of different austenitizing temperatures of 1323 and $1373 \mathrm{~K}$ after annealing, then, they were tempered between 673 and $873 \mathrm{~K}$. The results are summarized as follows: 


\section{As-cast state}

(1) The microstructure of each specimen consisted of primary austenite dendrite $\left(\gamma_{\mathrm{P}}\right)$ and $(\gamma+\mathrm{MC})$ and $\left(\gamma+\mathrm{M}_{2} \mathrm{C}\right)$ eutectics in specimens with 3 and $5 \% \mathrm{Cr}$. By contrast, $\left(\gamma+\mathrm{M}_{7} \mathrm{C}_{3}\right)$ eutectic appeared in specimens with $6 \% \mathrm{Cr}$ and more.

(2) With regard to the chemical composition of specimens in this study, the area fraction of $\gamma_{\mathrm{P}}$ decreased slightly, and $(\gamma+\mathrm{MC})$ eutectic decreased progressively. On the other hand, $\left(\gamma+\mathrm{M}_{2} \mathrm{C}\right)$ and $\left(\gamma+\mathrm{M}_{7} \mathrm{C}_{3}\right)$ eutectics increased as $\mathrm{Cr}$ content went up, except for the $6 \% \mathrm{Cr}$ specimen. When the $\mathrm{Cr}$ content increased to $6 \%$, the crystallization of $\left(\gamma+\mathrm{M}_{2} \mathrm{C}\right)$ eutectic was inhibited and that of $\left(\gamma+\mathrm{M}_{7} \mathrm{C}_{3}\right)$ eutectic was promoted.

\section{As-hardened state}

(1) The hardness increased slightly to the highest value at $5 \% \mathrm{Cr}$, and then decreased continuously as the $\mathrm{Cr}$ content increased. The low austenitizing temperature $1323 \mathrm{~K}$ resulted in greater hardness than high austenitizing temperature of $1373 \mathrm{~K}$.

(2) The volume fraction of retained austenite $\left(\mathrm{V}_{\gamma}\right)$ in ashardened state increased gradually to the highest value at $5 \% \mathrm{Cr}$ and, after that, it decreased progressively as $\mathrm{Cr}$ content rose. The higher austenitizing temperature showed a greater amount of $\mathrm{V} \gamma$ when the $\mathrm{Cr}$ content was over $5 \%$.

(3) The micro-hardness increased proportional to the $\mathrm{V} \gamma$. The maximum micro-hardness was obtained at $17 \%$ and $24 \% \mathrm{~V} \gamma$ in specimens hardened from $1323 \mathrm{~K}$ and $1373 \mathrm{~K}$, respectively.

\section{Tempered state}

(1) The secondary hardening was clearly found in all the tempered hardness curves. The maximum tempered hardness $\left(\mathrm{H}_{\mathrm{Tmax}}\right)$ was obtained at tempering between 773 and $798 \mathrm{~K}$ and it shifted to the lower temperature side when $\mathrm{Cr}$ content was over $6 \%$. Higher $\mathrm{H}_{\text {Tmax }}$ value was obtained by hardening from higher austenitizing temperature.

(2) The $V_{\gamma}$ decreased as the temperature increased, and it dropped steeply when the temperature got over $723 \mathrm{~K}$. The $\mathrm{V} \gamma$ value in the tempered specimen at the $\mathrm{H}_{\text {Tmax }}$ was overall less than $5 \%$.

(3) The hardness increased to the maximum value at about $4 \% \mathrm{~V} \gamma$ and decreased gradually as the $\mathrm{V} \gamma$ increased. Macro-hardness over $900 \mathrm{HV} 30$ and micro-hardness over $800 \mathrm{HV} 0.1$ were at $\mathrm{V} \gamma$ up to $10 \%$ and up to $18 \%$, respectively. At the $\mathrm{V} \gamma$ value of less than $2 \%$, the micro-hardness scattered broadly from 540 to 860 HV0.1 due to an increase in $\mathrm{Cr}$ carbide with lower hardness.

(4) The $\mathrm{H}_{T \max }$ value increased proportionally as the $\mathrm{V} \gamma$ value in the as-hardened state rose. A value of more than $17 \% \mathrm{~V} \gamma$ was found to be necessary to achieve the $\mathrm{H}_{\text {Tmax }}$ over $900 \mathrm{HV} 30$.
(5) The degree of secondary hardening $(\Delta \mathrm{Hs})$ decreased progressively as $\mathrm{Cr}$ content increased. The $\Delta \mathrm{Hs}$ rose with an increase in the $\mathrm{V} \gamma$ value in as-hardened state. It was found that the $\Delta \mathrm{Hs}$ more than $50 \mathrm{HV} 30$, which was necessary to obtain $\mathrm{H}_{\mathrm{Tmax}}$ value over $900 \mathrm{HV} 30$, was provided when the $\mathrm{V} \gamma$ in as-hardened state rose above $14 \%$.

\section{Acknowledgments}

The authors thank Chulalongkorn University for financial support given by "The 100th Anniversary Chulalongkorn University for Doctoral Scholarship" fund and "Overseas Research Experience Scholarship for Graduate Student" fund. In addition, we would like to give thanks to the Manufacturing and Metallurgical Engineering Research Unit, Faculty of Engineering, Mahasarakham University and Cast metals laboratory of the National Institute of Technology, Kurume College for usage of experimental devices.

\section{REFERENCES}

1) G. Laird, R. Gundlach and K. Rohrig: Abrasion-Resistance Cast Iron Handbook, (American Foundry Society, USA, 2000).

2) M. Hashimoto: Abrasion Wear Resistant Alloyed White Cast Iron for Pulverizing Mills, (2008) pp. 1-23.

3) G. Gevelmann and W. Theisen: Abrasion Wear Resistant Alloyed White Cast Iron for Pulverizing Mills, (2011) pp. 171-181.

4) M. Boccalini, Jr.: Abrasion Wear Resistant Alloyed White Cast Iron for Pulverizing Mills, (2011) pp. 123-142.

5) Y. Matsubara, N. Sasaguri and M. Hashimoto: The 4th Foundry Congress-Australia, (1996) pp. 251-261.

6) H.-Q. Wu, N. Sasaguri, Y. Matsubara and M. Hashimoto: AFS Trans. 140 (1996) 103-108.

7) I.R. Sare and B.K. Arnold: Metall. Mater. Trans. A 26 (1995) 17851793.

8) J.D. Watson, P.J. Mutton and I.R. Sare: Aust. Inst. Met. Forum 3 (1980) 74-88.

9) K.-H. Zum Gahr and D.V. Doane: Metall. Trans. A 11 (1980) 613-620.

10) J. Opapaiboon, P. Sricharoenchai, S. Inthidech and Y. Matsubara: Mater. Trans. 56 (2015) 720-725.

11) N. Sasaguri, Y. Yokomizo, K. Yamamoto and Y. Matsubara: Abrasion Wear Resistant Alloyed White Cast Iron for Pulverizing Mills, (2011) pp. 177-187.

12) T. Meebupha, S. Inthidech, P. Sricharoenchai and Y. Matsubara: Mater. Trans. 58 (2017) 655-662.

13) M. Hashimoto: Abrasion Wear Resistant Alloyed White Cast Iron for Pulverizing Mills, (2011) pp. 183-192.

14) W. Khanitnantharak, M. Hashimoto, K. Shimizu, K. Yamamoto, N. Sasaguri and Y. Matsubara: AFS Trans. 117 (2009) 435-444.

15) Y. Matsubara, N. Sasaguri, Y. Yokomizo and H.-Q. Wu: J. Jpn. Foundry Eng. Soc. 71 (1999) 183-189.

16) M. Hashimoto, O. Kubo and Y. Matsubara: ISIJ Int. 44 (2004) 372380 .

17) E.S. Lee, W.J. Park, J.Y. Jung and S. Ahn: Metall. Mater. Trans. A 29 (1998) 1395-1404

18) M. Hashimoto, O. Kubo, N. Sasaguri and Y. Matsubara: J. Jpn. Foundry Eng. Soc. 76 (2004) 205-211.

19) Y. Yokomizo, N. Sasaguri, K. Nanjo and Y. Matsubara: J. Jpn. Foundry Eng. Soc. 74 (2002) 691-698.

20) G. Powell and G. Laird: J. Mater. Sci. 27 (1992) 29-35. 